\title{
Varietal verification of Thai rice using ultrathin layer isoelectric focusing of seed proteins
}

\author{
Pakanan Jiamtae $^{\mathrm{a}}$, Damrongvudhi Onwimol ${ }^{\mathrm{a}, *}$, Wanchai Chanprasert ${ }^{\mathrm{a}}$, Thammasak Thongket ${ }^{\mathrm{b}}$, \\ Ancharee Prasertsak ${ }^{c}$ \\ a Department of Agronomy, Faculty of Agriculture, Kasetsart University, Bangkok 10900 Thailand \\ b Department of Horticulture, Faculty of Agriculture at Kamphaeng-Saen, Kasetsart University, \\ Nakhon Pathom 73140 Thailand \\ c Bureau of Rice Research and Development, Rice Department, Bangkok 10900 Thailand
}

*Corresponding author, e-mail: damrongvudhi.o@ku.th

Received 13 Jan 2016

Accepted 19 Apr 2017

\begin{abstract}
A suitable extraction solvent of seed protein for the identification of Thai rice varieties was determined for use in ultrathin layer isoelectric focusing (UTLIEF). Breeder seeds of 16 varieties were used and 3 extraction buffers, namely, phosphate buffer, $\mathrm{NaCl}$, and water (with gel $\mathrm{pH} 2-9$ ) were compared. The most suitable extraction buffer was phosphate buffer, which gave the highest efficacy of identification (98\%) compared to $\mathrm{NaCl}(90 \%)$ and water (89\%). The phosphate buffer was then tested in varietal verification using examination of individual seeds and testing bulk samples. The results show that the method of examination of individual seeds could clearly differentiate the contaminant variety from the tested variety, while testing bulk samples (10 seeds) could identify the contaminant variety when the ratio of seed number of the contaminant variety to the tested variety was 4-6 and higher. It can be concluded that phosphate buffer is suitable to be used in UTLIEF which is a promising method for varietal verification of Thai rice.
\end{abstract}

KEYWORDS: indica rice, contaminant varieties, UTLIEF

\section{INTRODUCTION}

The demand for rice seed in Thailand is almost one million tonnes each year, while good quality seed supply by all stakeholders is only 400000 tonnes $^{1}$. In addition to the shortage problem, seed quality is uncertain and often low $(70 \%$ of the rice seed samples taken from the markets did not meet standard defined in the seed legislation of Thailand ${ }^{2}$ ). One of the problems, apart from low germination and low physical purity, is seed contamination by other rice varieties which is an extremely important characteristic especially for rice production in the irrigated areas of the central region of Thailand where more than 10 varieties are grown ${ }^{3}$. The Plants Act, B.E. 2518 (1975), as amended by the Plants Act (No. 3), B.E. 2550 (2007) of Thailand, sets the maximum limit for other-variety contamination at 20 seeds per $500 \mathrm{~g}$. Consequently, variety testing is very important in rice seed production and marketing in Thailand.
There are several techniques for testing for other varieties both in the laboratory and in the field such as the morphological method, the physiological and biochemical method, and the growout test ${ }^{4}$. The morphological method relies heavily on the experience of the seed analyst because the results are quite subjective and seed morphology may vary when the seed is grown under different environments. The grow-out or field plot test is laborious, time-consuming, and the results are also inconsistent due to environmental stresses ${ }^{5,6}$. In biochemical testing, the DNA fingerprint technique is normally employed for testing rice variety contamination in many cases and is considered to be accurate and reliable, but it is expensive and timeconsuming. Furthermore, this method may not be appropriate for rice variety testing because of the complexity and difficulty of DNA extraction. Recently, a modification of isoelectric focusing (IEF) on polyacrylamide gel with a thickness of $0.15 \mathrm{~mm}$ ultrathin layer isoelectric focusing (UTLIEF) has 
been used for variety and genetic purity testing in many crops. This technique offers a faster, safer, and cheaper way to verify varieties using the separation of storage protein in the seed ${ }^{7,8}$. Isoelectric focusing is the separation of amphoteric substances (carrier ampholytes). The ampholytes migrate along the $\mathrm{pH}$-gradient under the influence of electrical forces between electrodes until they arrive at their isoelectric point, where the net external electrical charge is zero and they become immobilized ${ }^{9}$. At the isoelectric point, storage protein can be seen on an electrophoretogram of the polyacrylamide gel.

The UTLIEF technique has been used to identify varieties within a species. An experiment with tomato revealed that 8 varieties out of 11 could be identified using UTLIEF ${ }^{10}$ and a positive result with the UTLIEF technique for cucumber varietal identification was reported ${ }^{8}$. In a study on the identification of seed proteins in 20 rice varieties (12 japonica and 8 indica varieties) it was found that 8 of the indica in China were clearly identified, while the japonica could be categorized into 2 groups ${ }^{11}$. Hence varietal verification using the UTLIEF technique is interesting and promising for use with Thai rice. Under the ISTA rules ${ }^{12}$, 2-chloroethanol is recommended as the standard protein extract buffer, because it can dissolve well seed storage proteins of several species. Hence it may be very successful when applied with unknown species. However, 2-chloroethanol is not a permitted substance for use in Thailand because it has been classified by the Ministry of Defence as an explosive agent ${ }^{8}$. Hence other protein buffers suitable for the extraction of storage protein in rice seed should be evaluated. The objectives of this study were to evaluate suitable buffers for use in UTLIEF to identify Thai rice varieties and to determine variety testing methods for possible routine use in seed testing laboratories.

\section{MATERIALS AND METHODS}

\section{Suitable buffer for varietal verification of Thai rice using UTLIEF}

Plant materials: Breeder seeds of 16 varieties (all indica) widely grown in Thailand (especially in the central region of Thailand): RD29, RD31, RD41, RD47, RD49, RD51, RD15, RD6, Pathum Thani 1 (PTT1), Suphan Buri 1 (SPR1), Suphan Buri 2 (SPR2), Suphan Buri 60 (SPR60), Suphan Buri 90 (SPR90), Phitsanulok 2 (PSL2), Chai Nat 1 (CNT1), and Khao Dawk Mali 105 (KDML105) were obtained from the Rice Department, Ministry of Agriculture and Cooperatives. All seed samples were stored at $5^{\circ} \mathrm{C}$ during experimentation.

Protein extraction: To determine the most suitable extraction buffer for seed storage protein of Thai rice, three extraction buffers were compared in this study: (1) deionized water; (2) phosphate buffer: $0.194 \mathrm{~g} \mathrm{~K}_{2} \mathrm{HPO}_{4}, 0.528 \mathrm{~g} \mathrm{KH}_{2} \mathrm{PO}_{4}, 0.38$ g ethylenediaminetetraacetic acid (EDTA), $1 \mathrm{~g}$ dithioerythritol (DTE), and $25 \mathrm{ml}$ glycerin in 11 deionized water; and (3) $5 \mathrm{mM} \mathrm{NaCl}$ solution. Bulk samples of 100 seeds of each variety were ground and $100 \mathrm{mg}$ of ground seed was placed in $1.5 \mathrm{ml}$ microcentrifuge tubes; then, after the addition of $300 \mu l$ of each extraction buffer, the tubes were frozen overnight at $-20^{\circ} \mathrm{C}$, then centrifuged at $1000 \mathrm{~g}$ for $5 \mathrm{~min}$. The supernatant was transferred to a new tube and again centrifuged at $1000 \mathrm{~g}$ for $5 \mathrm{~min}$. This supernatant was used for UTLIEF.

UTLIEF gel preparation and IEF: UTLIEF gels were cast on polyester support films ${ }^{13}$ (Gel-Stick, ProTec). Adhesive tape, $0.1 \mu \mathrm{m}$ thick, was used as the spacer along the long sides of a cover glass plate. The polymerization solution for 10 gels contained $16 \mathrm{~g}$ urea, $1.6 \mathrm{~g}$ taurine, $50 \mathrm{ml}$ acrylamide $(\mathrm{T}=7 \%$, $\mathrm{C}=2 \%$ ), $4.4 \mathrm{ml}$ of $\mathrm{pH} 2-9$ ampholytes (Servalyt, Germany), $50 \mu 1 N, N, N^{\prime}, N^{\prime}$-tetramethylethylenediamine, and $300 \mu \mathrm{l}$ of $20 \%(\mathrm{w} / \mathrm{v})$ ammonium peroxydisulphate $^{6}$. The isoelectric focusing was carried out on an IEF-SYS horizontal electrophoresis unit ${ }^{8}$ (Desaphor HF210). Briefly, one anodal electrode was placed on the top and one cathodal electrode was placed on the bottom of the gel. An application strip was placed on top of the gel surface about $0.5 \mathrm{~mm}$ away from the anode strip. This technique was called the single focusing technique. Then, for each sample, $19 \mu \mathrm{l}$ of seed protein was dropped into each well of the application strip. The unit was connected to a cooling apparatus to cool the gel surface down to $8^{\circ} \mathrm{C}$. A power supply unit (Consort E833) provided multiple steps for $70 \mathrm{~min}$. After focusing, gels were fixed in $12 \%(\mathrm{w} / \mathrm{v})$ trichloroacetic acid for $20 \mathrm{~min}$, then stained in Coomassie Brilliant Blue solution containing $0.015 \%(\mathrm{w} / \mathrm{v}$ ) Coomassie R 250 and $0.045 \%(\mathrm{w} / \mathrm{v}$ ) Coomassie G 250, 11\% (v/v) acetic acid, $18 \%(\mathrm{v} / \mathrm{v})$ ethanol, and $71 \%(\mathrm{v} / \mathrm{v})$ water for $50 \mathrm{~min}$ and finally destained in a solution of $30 \%(\mathrm{v} / \mathrm{v})$ ethanol, $5 \%(\mathrm{v} / \mathrm{v})$ acetic acid, and $65 \%$ (v/v) water for $20 \mathrm{~min}$. After rinsing with water, the gels were air dried overnight at room temperature. When covered with transparent adhesive tape, the gels could be stored before interpretation of the result is made ${ }^{14}$. The efficacy of a suitable buffer 
was calculated as $\left(N-N_{\text {nd }}\right) / N$, where $N$ is the number of pairs and $N_{\text {nd }}$ the non-different pair.

\section{Selecting and evaluating some available methods for testing other varieties contaminated in rice seed}

Variety test by UTLIEF using test of individual seeds: The suitable solvent and optimal conditions from the previous experiment were used in this experiment to develop a method for testing other-variety contamination. KDML105 and CNT1 were designated as the main variety and the contaminant variety, respectively, as these 2 varieties are difficult to distinguish from each other visually. The protein extraction method was performed following the procedures mentioned in the previous experiment. The IEF technique was designed by producing 100 lanes of single seed samples in one gel using the double focusing technique, which provides highthroughput analysis by positioning a single cathode at the centre of the gel slab with two anodes, one on each of the two long edges of the gel parallel to the cathode ${ }^{15}$. Since 100 lanes were available on the plate, the experiment was prepared by randomly mixing 9 seeds (arbitrary number) of the contaminant variety (CNT1) with 91 seeds of the main variety (KDML105) and applying the double focusing technique. Polymorphism protein profiling, or protein banding, between the main variety and the contaminant variety were investigated.

Variety test with UTLIEF using testing of bulk samples (10 seeds): This method was introduced with the aim of reducing both the cost and testing resources by mixing 10 seeds of the contaminant and the main variety in different proportions and using this mixture as one sample for a single testing lane on the plate. If the UTLIEF technique could detect a contaminant variety at a low proportion, then this testing method could be used to estimate the genetic purity of a seed lot as well as for setting accept/reject criteria based on a given threshold ${ }^{16}$. The suitable solvent and optimal conditions for UTLIEF from the previous experiment were also used in this experiment. The protein extraction method was also performed following the procedures mentioned before. Seeds of CNT1, the contaminant variety, were intentionally mixed with the main variety (KDML105) in 11 proportions ranging from 0:10 seeds to $10: 0$ seeds to make a dilution series for contamination testing $(0: 10,1: 9,2: 8,3: 7,4: 6,5: 5$, $6: 4,7: 3,8: 2,9: 1$, and 10:0, respectively). Each testing mixture, consisting of bulk seeds of the main and the contaminant variety was prepared in 3 lanes (replicates) using the single focusing technique. Thus the intensity of alien bands, or adulterated protein bands, from the contaminant variety was evaluated and polymorphic protein bands between the main variety and the contaminant variety were investigated.

\section{RESULTS}

\section{Suitable buffer for varietal verification of Thai rice using UTLIEF}

In this study, three extraction buffers, i.e., deionized water, phosphate buffer, and $\mathrm{NaCl}$ solution were compared to determine the most suitable extraction buffer for seed storage protein of Thai rice. Protein extraction using phosphate buffer and separation in the gel $\mathrm{pH}$ range 2-9 showed 9 polymorphic protein bands of the 16 rice varieties tested in this experiment (Fig. 1 and Fig. 2). The efficacy of identification was $98 \%$. There were 3 pairs that could not be differentiated from each other, i.e., PTT1 versus PSL2, CNT1 versus SPR2, and SPR90 versus SPR1 while the other 10 varieties could be individually identified (Table 1).

The extraction using $5 \mathrm{mM} \mathrm{NaCl}$ showed 8 polymorphic protein bands (Fig. 3 and Fig. 4) and the efficacy of identification was $90 \%$. This condition could not differentiate 13 pairs of rice varieties from each other, i.e., RD29 versus RD31, RD29 versus RD49, RD29 versus KDML105, RD31 versus RD49, RD31 versus KDML105, RD49 versus KDML105, RD51 versus SPR60, PSL2 versus SPR2, PTT1 versus SPR1, SPR2 versus RD15, SPR2 versus SPR90, and RD15 versus SPR90 and only 4 varieties were individually identified (RD41, RD47, CNT1, and RD6) (Table 2).

For the extraction using deionized water as an extraction buffer, it was found that there were 10 polymorphisms (Fig. 5 and Fig. 6) and the efficacy of identification was $89 \%$. There were 15 pairs of rice varieties that could not be differentiated from each other and only SPR1 and RD6 were individually identified (Table 3 ).

The variety groupings identified by these three extraction buffers are also compared. The phosphate buffer could separate the 16 rice varieties into 10 individuals and 3 pairs, $\mathrm{NaCl}$ could separate into 4 individuals, 2 pairs and 2 groups of 4 , while water could separate into 2 individuals, 3 pairs and 2 groups. Thus phosphate buffer was the most suitable buffer among these three extraction buffers and it showed promise as a buffer for Thai rice 


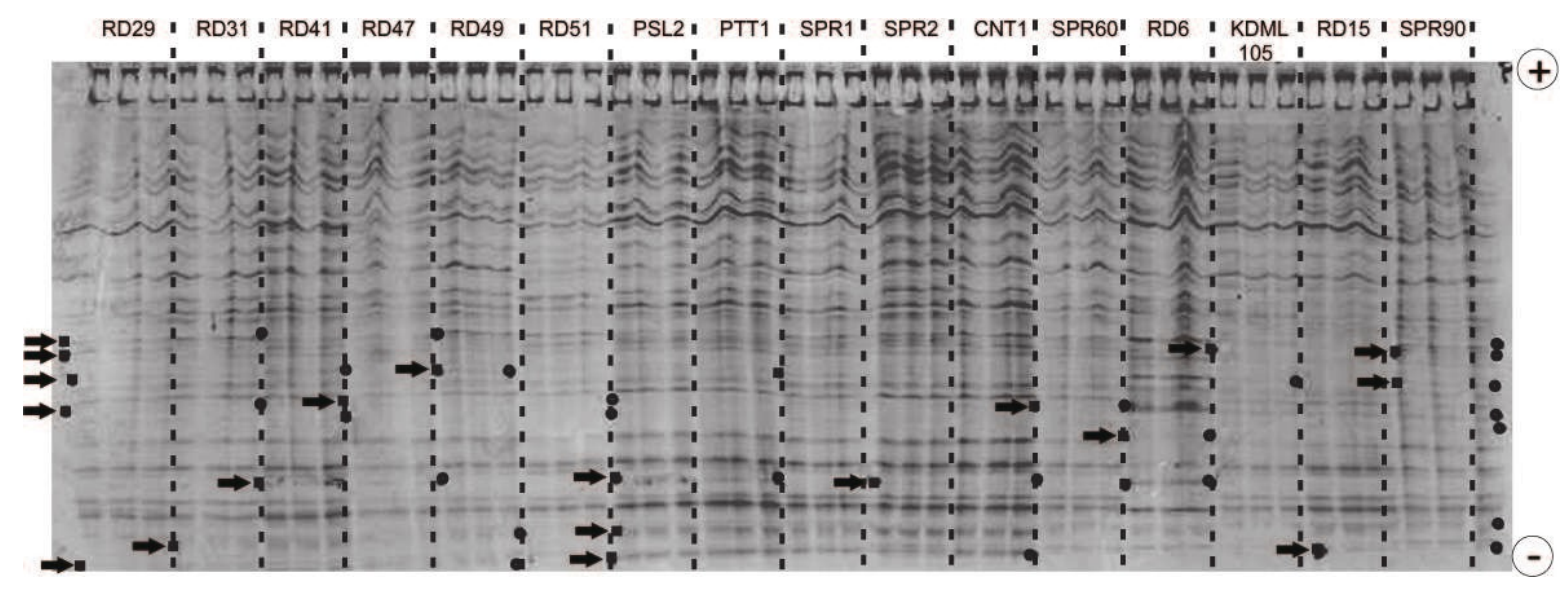

Fig. 1 UTLIEF profile of protein bands after performing phosphate buffer together with gel pH 2-9 (+: anode, -: cathode; arrows: existing polymorphic protein bands; squares: start, circles: end).

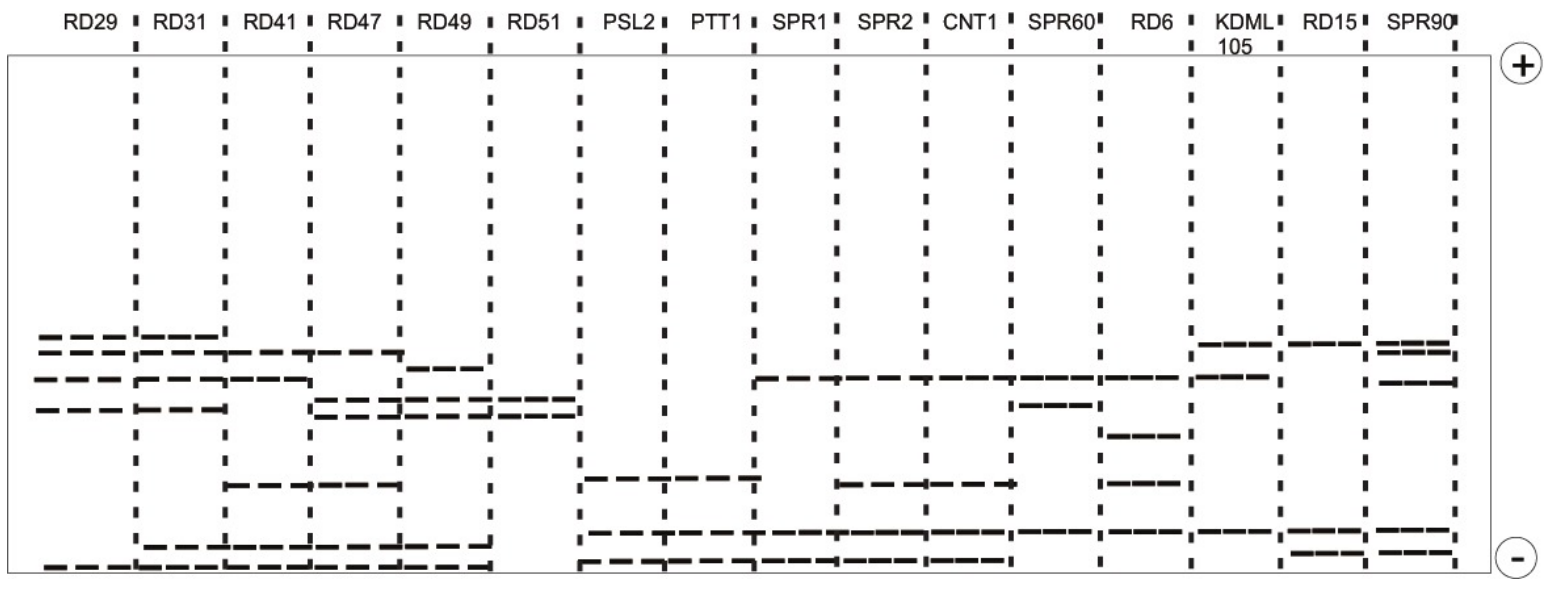

Fig. 2 Diagram of UTLIEF profile of protein bands after performing phosphate buffer together with gel pH 2-9; +: anode, -: cathode.

Table 1 Pairwise polymorphic bands from 16 cultivars rice seed extracted by using phosphate buffer and gel pH 2-9. Non polymorphism is indicated in bold.

\begin{tabular}{|c|c|c|c|c|c|c|c|c|c|c|c|c|c|c|c|c|}
\hline & $\mathrm{RD} 29$ & RD31 & RD41 & $\mathrm{RD} 47$ & RD49 & RD51 & PSL2 & PTT1 & SPR1 & SPR2 & CNT1 & SPR60 & RD6 & KDML105 & RD15 & SPR90 \\
\hline RD29 & 0 & & & & & & & & & & & & & & & \\
\hline RD31 & 1 & 0 & & & & & & & & & & & & & & \\
\hline RD41 & 5 & 3 & 0 & & & & & & & & & & & & & \\
\hline RD47 & 5 & 4 & 2 & 0 & & & & & & & & & & & & \\
\hline RD49 & 1 & 1 & 4 & 4 & 0 & & & & & & & & & & & \\
\hline RD51 & 3 & 3 & 7 & 4 & 3 & 0 & & & & & & & & & & \\
\hline PSL2 & 4 & 4 & 2 & 2 & 4 & 5 & 0 & & & & & & & & & \\
\hline PTT1 & 5 & 3 & 2 & 3 & 2 & 5 & 0 & 0 & & & & & & & & \\
\hline SPR1 & 2 & 1 & 3 & 4 & 3 & 5 & 2 & 2 & 0 & & & & & & & \\
\hline SPR2 & 3 & 2 & 1 & 2 & 3 & 6 & 1 & 1 & 1 & 0 & & & & & & \\
\hline CNT1 & 3 & 2 & 1 & 3 & 2 & 6 & 1 & 1 & 1 & 0 & 0 & & & & & \\
\hline SPR60 & 2 & 1 & 4 & 4 & 2 & 4 & 3 & 3 & 3 & 2 & 3 & 0 & & & & \\
\hline RD6 & 4 & 4 & 3 & 5 & 3 & 4 & 2 & 2 & 2 & 1 & 1 & 1 & 0 & & & \\
\hline KDML105 & 4 & 2 & 4 & 6 & 2 & 3 & 3 & 3 & 1 & 2 & 2 & 2 & 3 & 0 & & \\
\hline RD15 & 4 & 3 & 3 & 4 & 4 & 4 & 2 & 4 & 2 & 3 & 3 & 3 & 5 & 2 & 0 & \\
\hline SPR90 & 2 & 1 & 1 & 5 & 3 & 4 & 2 & 2 & 0 & 1 & 1 & 1 & 2 & 2 & 1 & 0 \\
\hline
\end{tabular}




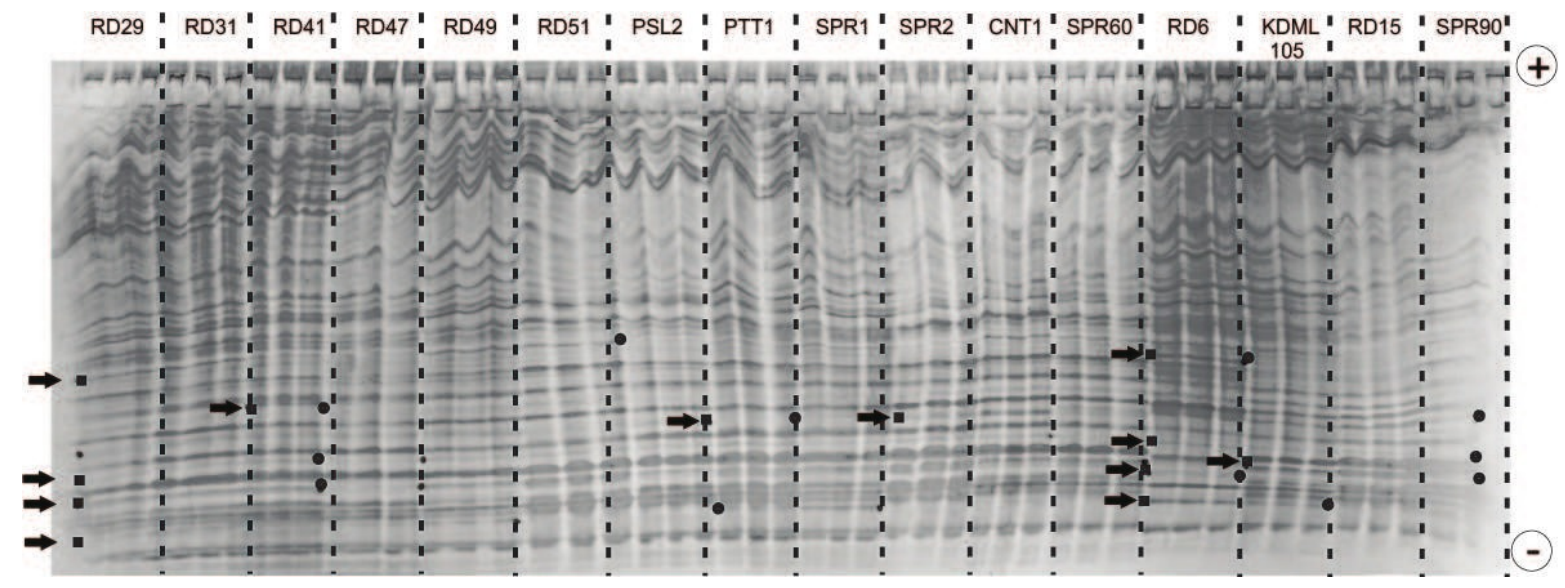

Fig. 3 UTLIEF profile of protein bands after performing $\mathrm{NaCl}$ solution together with gel pH 2-9 (+: anode, -: cathode; arrows: existing polymorphic protein bands; squares: start, circles: end).

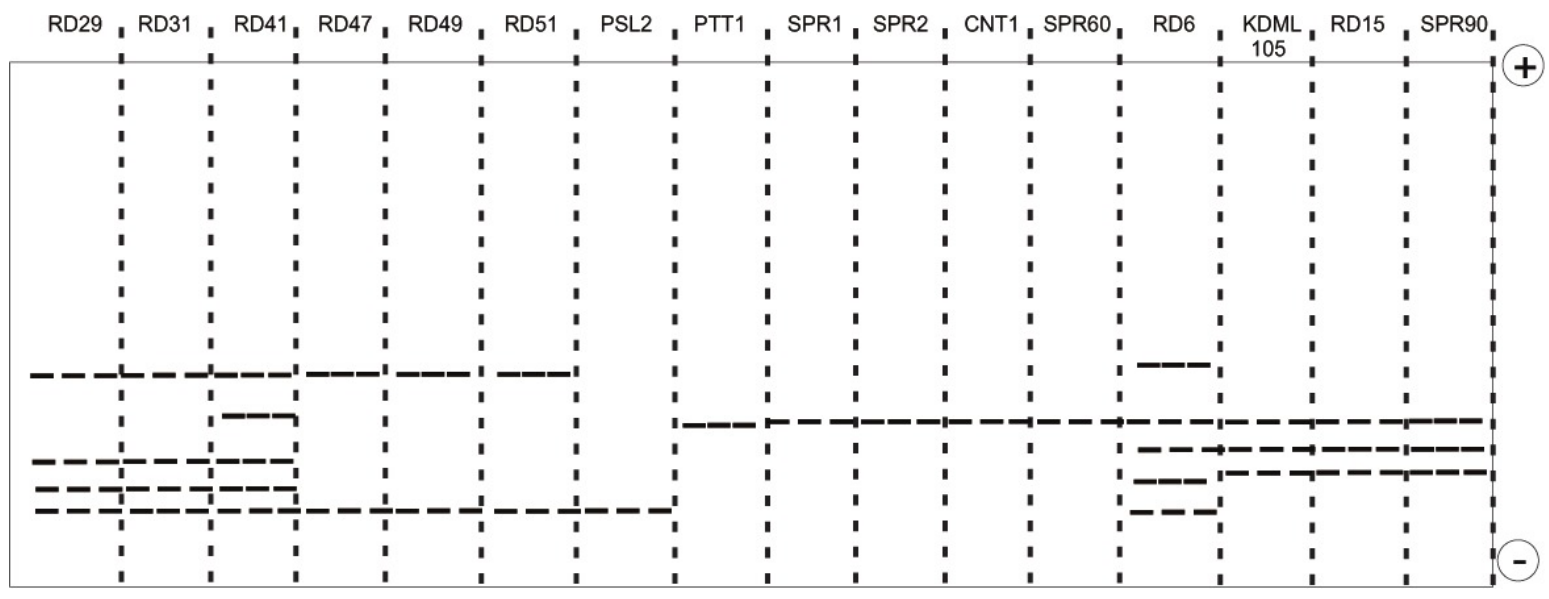

Fig. 4 Diagram of UTLIEF profile of protein bands after performing $\mathrm{NaCl}$ solution together with gel pH 2-9; +: anode, -: cathode.

Table 2 Pairwise polymorphic bands from 16 cultivars rice seed extracted by using $\mathrm{NaCl}$ solution and gel pH 2-9. Non polymorphism is indicated in bold.

\begin{tabular}{|c|c|c|c|c|c|c|c|c|c|c|c|c|c|c|c|c|}
\hline & RD29 & RD31 & RD41 & RD47 & RD49 & RD51 & PSL2 & PTT1 & SPR1 & SPR2 & CNT1 & SPR60 & RD6 & KDML105 & RD15 & SPR90 \\
\hline RD29 & 0 & & & & & & & & & & & & & & & \\
\hline RD31 & 0 & 0 & & & & & & & & & & & & & & \\
\hline RD41 & 1 & 1 & 0 & & & & & & & & & & & & & \\
\hline RD47 & 2 & 2 & 3 & 0 & & & & & & & & & & & & \\
\hline RD49 & 0 & 0 & 1 & 2 & 0 & & & & & & & & & & & \\
\hline RD51 & 1 & 1 & 1 & 2 & 1 & 0 & & & & & & & & & & \\
\hline PSL2 & 1 & 1 & 2 & 3 & 1 & 1 & 0 & & & & & & & & & \\
\hline PTT1 & 2 & 2 & 4 & 4 & 3 & 2 & 2 & 0 & & & & & & & & \\
\hline SPR1 & 5 & 4 & 3 & 2 & 2 & 2 & 3 & 0 & 0 & & & & & & & \\
\hline SPR2 & 1 & 1 & 2 & 2 & 1 & 1 & 0 & 2 & 2 & 0 & & & & & & \\
\hline CNT1 & 1 & 1 & 1 & 1 & 1 & 1 & 2 & 3 & 3 & 1 & 0 & & & & & \\
\hline SPR60 & 1 & 1 & 1 & 1 & 2 & 0 & 1 & 3 & 1 & 2 & 1 & 0 & & & & \\
\hline RD6 & 3 & 2 & 3 & 2 & 2 & 3 & 3 & 3 & 3 & 3 & 5 & 3 & 0 & & & \\
\hline KDML105 & 0 & 0 & 1 & 3 & 0 & 1 & 2 & 2 & 3 & 2 & 2 & 1 & 3 & 0 & & \\
\hline RD15 & 2 & 2 & 3 & 2 & 2 & 1 & 0 & 2 & 2 & 1 & 1 & 3 & 2 & 2 & 0 & \\
\hline SPR90 & 2 & 2 & 3 & 2 & 2 & 1 & 0 & 2 & 2 & 0 & 1 & 2 & 3 & 2 & 0 & 0 \\
\hline
\end{tabular}




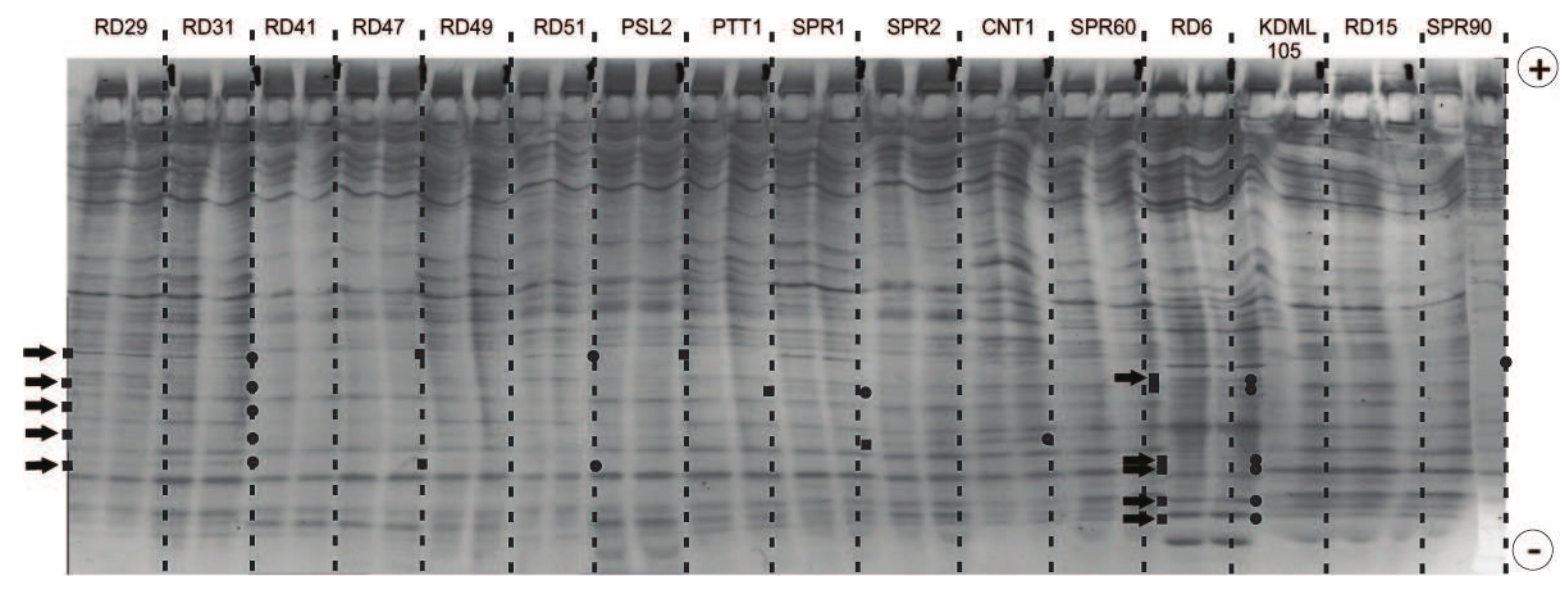

Fig. 5 UTLIEF profile of protein bands after performing deionized water together with gel pH 2-9 (+: anode, - : cathode; arrows: existing polymorphic protein bands; squares: start, circles: end).

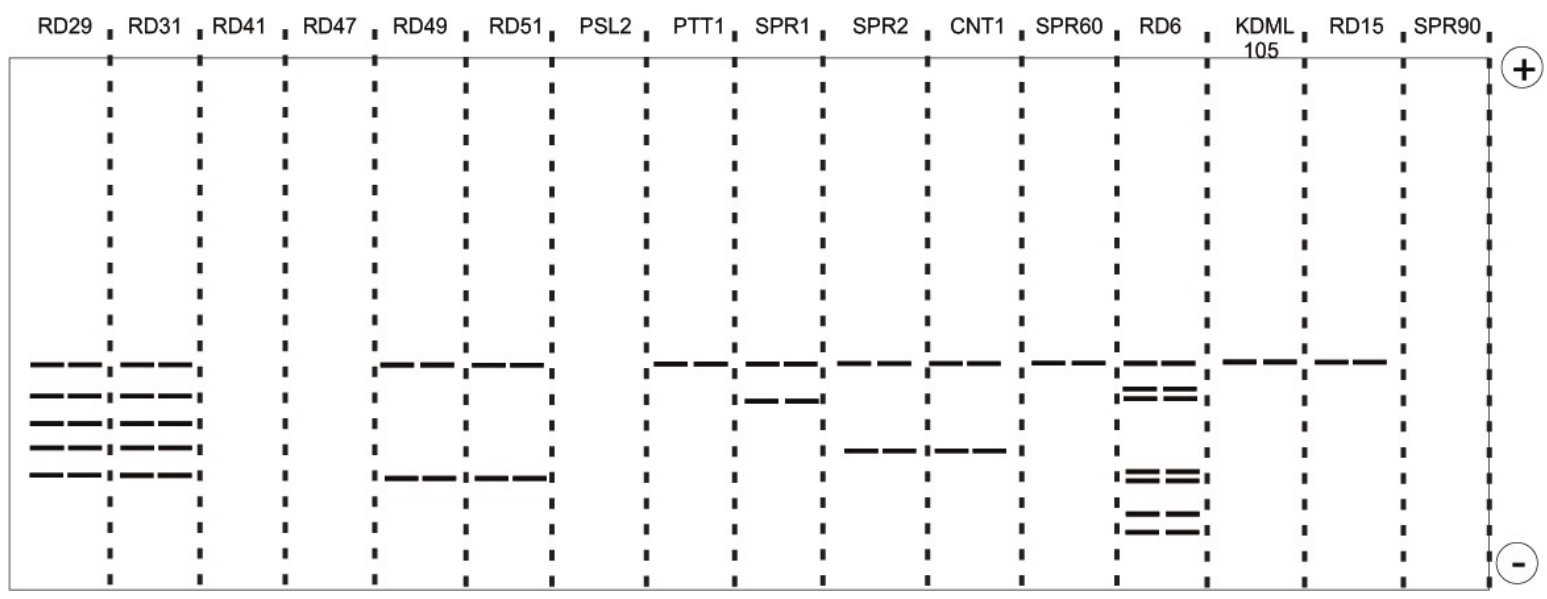

Fig. 6 Diagram of UTLIEF profile of protein bands after performing deionized water together with gel pH 2-9; +: anode, -: cathode.

Table 3 Pairwise polymorphic bands from 16 cultivars rice seed extracted by using deionized water and gel pH 2-9. Non polymorphism is indicated in bold.

\begin{tabular}{|c|c|c|c|c|c|c|c|c|c|c|c|c|c|c|c|c|}
\hline & RD29 & RD31 & RD41 & RD47 & RD49 & RD51 & PSL2 & PTT1 & SPR1 & SPR2 & CNT1 & SPR60 & RD6 & KDML105 & RD15 & SPR90 \\
\hline RD29 & 0 & & & & & & & & & & & & & & & \\
\hline RD31 & 0 & 0 & & & & & & & & & & & & & & \\
\hline RD41 & 5 & 5 & 0 & & & & & & & & & & & & & \\
\hline RD47 & 5 & 5 & 0 & 0 & & & & & & & & & & & & \\
\hline RD49 & 3 & 3 & 2 & 2 & 0 & & & & & & & & & & & \\
\hline RD51 & 3 & 3 & $\overline{2}$ & $\overline{2}$ & 0 & 0 & & & & & & & & & & \\
\hline PSL2 & 5 & 5 & 0 & 0 & 2 & 2 & 0 & & & & & & & & & \\
\hline PTT1 & 4 & 4 & 1 & 1 & 1 & 1 & 1 & 0 & & & & & & & & \\
\hline SPR1 & 3 & 3 & 2 & 2 & 2 & 2 & 2 & 1 & 0 & & & & & & & \\
\hline SPR2 & 3 & 3 & 2 & 2 & 2 & 2 & 2 & 1 & 2 & 0 & & & & & & \\
\hline CNT1 & 3 & 3 & 2 & 2 & 3 & 3 & 2 & 1 & $\overline{1}$ & 0 & 0 & & & & & \\
\hline SPR60 & 4 & 4 & 1 & 1 & 2 & 2 & 1 & 0 & 1 & 1 & 1 & 0 & & & & \\
\hline RD6 & 8 & 8 & 10 & 10 & 6 & 6 & 9 & 7 & 8 & 7 & 7 & 6 & 0 & & & \\
\hline KDML105 & 4 & 4 & 1 & 1 & 1 & 1 & 1 & 0 & 1 & 1 & 1 & 0 & 6 & 0 & & \\
\hline RD15 & 4 & 4 & 1 & 1 & 1 & 1 & 1 & 0 & 1 & 1 & 1 & 0 & 6 & 0 & 0 & \\
\hline SPR90 & 4 & 4 & 1 & 1 & 1 & 1 & 1 & 0 & 1 & 1 & 1 & 0 & 6 & 0 & 0 & 0 \\
\hline
\end{tabular}




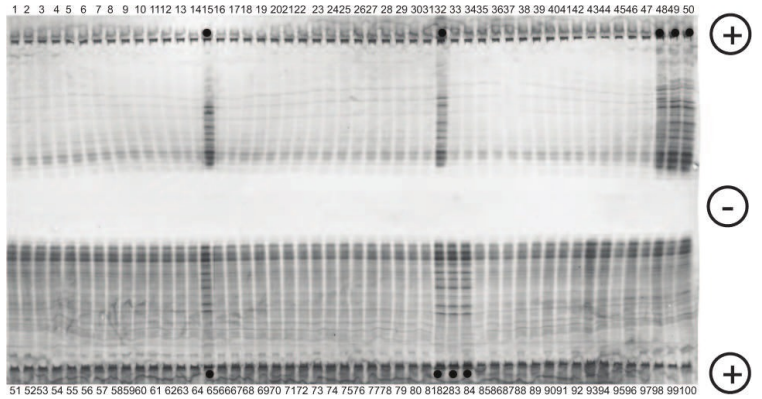

Fig. 7 UTLIEF profile of phosphate buffer extracted seed proteins of KDML105 and CNT1, marked with black circles, carried out on gel with pH gradient of 2-9 (+: anode, -: cathode).

varietal verification in UTLIEF, with the gel $\mathrm{pH}$ in the range $2-9$.

\section{Selecting and evaluating some available methods for testing other varieties contaminated in rice seed}

As it was found that UTLIEF with phosphate buffer was suitable for identifying Thai rice varieties, this testing method was further evaluated to test other varieties (OT) contaminated with Thai rice seed lots using two methods: testing individual seeds and testing bulk samples. The results of testing individual seeds are shown in Fig. 7. Nine seeds of CNT1, marked with spots, were clearly separated from KDML105 according to the UTLIEF profile. Thus the resolution of UTLIEF can reach a low as $1 \%$. This method can detect one off-type seed out of 100 single seed.

Testing bulk samples (10 seeds) was introduced to test other-variety contamination at $0.1 \%$ (or 1 contaminant seed of other variety per 1000 seeds of main variety). Testing bulk samples used the double focusing technique that contains 100 samples per one IEF gel so that 1000 seeds could be tested. The results shown in Fig. 8 and Fig. 9 reveal that the UTLIEF technique could differentiate other-variety contamination in the main variety at a proportion of 4:6 or higher (from 4:6 up to 9:1 of contaminant variety versus the main variety, respectively). Fewer than 4 seeds of the contaminant variety of $(1: 9,2: 8$, and 3:7) in the mixture could not be differentiated by this bulk sample method.

\section{DISCUSSION}

Variety verification has become an important aspect in the production and business of rice seed in Thailand. During the past four decades, numerous rice

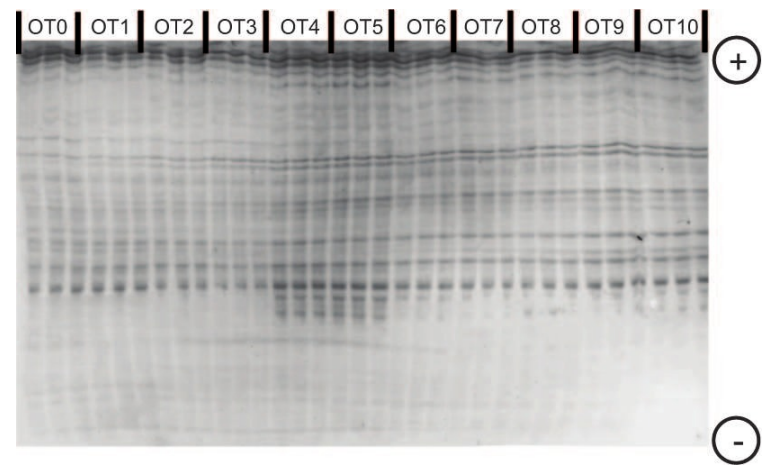

Fig. 8 UTLIEF profile of phosphate buffer extracted seed proteins of KDML105 and CNT1 carried out on gel with $\mathrm{pH}$ gradient of 2-9. Mixing proportions between seeds of contaminant variety and main variety (CNT1 and KDML105, respectively) indicated on the top of each lane. OT0 = KDML105 10:0 CNT1, OT1 = KDML105 9:1 CNT1, OT2 = KDML105 8:2 CNT1, OT3= KDML105 7:3 CNT1, OT4 = KDML105 6:4 CNT1, OT5 = KDML105 5:5 CNT1, OT6 = KDML105 4:6 CNT1, OT7 = KDML105 3:7 CNT1, OT8 = KDML105 2:8 CNT1, OT9 = KDML105 1:9 CNT1, OT10 = KDML105 0:10 CNT1; +: anode, - : cathode

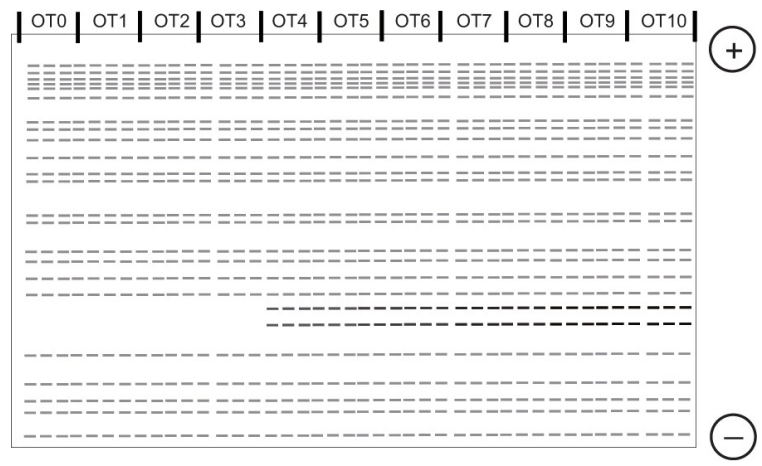

Fig. 9 Diagram of UTLIEF profile of bulk sampling method (OT1 to OT3 show the protein bands of the mixture of 10 seeds similar to those of OT0 of KDML105 while OT4 to OT9 present the protein bands of the mixture of 10 seeds which can distinguish the contaminant variety, Chai Nat 1 or OT10). OT0-OT10 as in Fig. 8; +: anode, -: cathode.

varieties have been released and nowadays almost 20 varieties are commercially grown in the central region of Thailand ${ }^{3}$. Consequently, contamination with other varieties has been a problem causing many disputes over the last few years. In the seed legislation of Thailand, a maximum allowance of 20 seeds per $500 \mathrm{~g}$ was set for other-variety contamination in a certified seed. Varietal verification based on morphological traits may not be appropriate and 
reliable because some varieties may be similar and difficult to distinguish. Ultrathin layer isoelectric focusing (UTLIEF) of seed storage proteins is a laboratory method that has great discriminative power, needs a shorter testing time, and involves lower cost than other electrophoretic methods ${ }^{7,17,18}$. UTLIEF has been used successfully to test the hybrid purity of tomato, maize, and sunflower and to identify tomato and rice varieties $6,7,11,17$. In the current study, UTLIEF was used to identify 16 rice varieties commercially grown in Thailand by comparing three extract buffers, namely, phosphate, $5 \mathrm{mM} \mathrm{NaCl}$, and deionized water. It was found that phosphate buffer was the most suitable with an efficacy of identification of $98 \%$. The quantity of polymorphic protein bands in this study revealed the quantity of protein which had been evaluated by Bradford protein assay ${ }^{19}$. In other words, the extraction buffer was able to extract a high quantity of the storage protein and provided a high number of polymorphic protein bands. The phosphate buffer could extract a high quantity of indica rice seed storage protein when compared to $5 \mathrm{mM} \mathrm{NaCl}$ solution and deionized water. This result in rice was in contrast with sweet corn and cucumber where the number of polymorphic bands did not depend on the quantity of protein ${ }^{14,20}$. However, for the identification of indica rice varieties, there was a study that identified seed proteins of 20 rice varieties using UTLIEF with phosphate buffer ${ }^{11}$. It was found that 8 varieties of indica rice were individually identified while 12 varieties of japonica rice could not be clearly identified with only 2 groups being separated ${ }^{11}$. UTLIEF technique has also been applied for genetic purity testing in hybrid rice using 2-chloroethanol as the extraction buffer at $\mathrm{pH}$ range 5-8 and found that the polymorphisms of male marker bands, female marker bands and F1 hybrid were different ${ }^{6}$. UTLIEF was also used to identify four commercial F-1 hybrid cucumbers by using water as an extraction solvent and had proposed to use a $\mathrm{pH}$ range 6-9 of protein band as a marker ${ }^{14}$. In other methods, Inter Simple Sequence Repeat (ISSR) markers could clearly identify four varieties of rice from each other with $100 \%$ identification efficacy ${ }^{18}$. In comparison to the UTLIEF method of the present study, the efficacy of identification was nearly the same (98\%) but UTLIEF is less complicated and cheaper than the ISSR technique.

Rice seed contains a high amount of glutelins so called oryzenin that can be extracted by phosphate buffer ${ }^{21}$. While 2-chloroethanol is generally used as the standard protein extraction buffer recom- mended by ISTA ${ }^{12}$, it is not available in Thailand because it is prohibited by the Ministry of Defence and, consequently, was not included in the present study. In this study, the phosphate buffer was found to be reasonably suitable with a high efficacy of identification; hence phosphate buffer can be recommended as a key protein extraction buffer for varietal verification of indica rice using the UTLIEF technique. The phosphate buffer could classify 10 Thai varieties independently RD29, RD31, RD41, RD47, RD49, RD51, SPR 60, RD6, KDML105, and RD15. In Thailand, the three varieties RD31, RD47, and RD41 are ranked highest in terms of production in the main rice growing area in central Thailand ${ }^{3}$ and these three varieties could be individually distinguished by the UTLIEF technique. Although there were three pairs of rice varieties that could not be differentiated from each other (PTT1 versus PSL2, CNT1 versus SPR2 and SPR90 versus SPR1), this technique can be further developed to verify these varieties if a suitable extraction buffer and gel $\mathrm{pH}$ gradient are chosen ${ }^{12}$. Hence this technique shows promise for varietal verification of the commercial rice in Thailand.

There are several techniques that can be used to test for other varieties such as the morphological method, the physiological and biochemical method, and the grow-out test ${ }^{4}$. However, it is rather difficult to identify other varieties in rice seed using morphological characteristics, especially for those involved in seed certification and seed legislation because there are no xenia effects as with maize seed ${ }^{22}$. A quick and reliable test for varietal verification of 23 rice varieties using five different chemical tests (phenol, modified phenol, $\mathrm{NaOH}, \mathrm{FeSO}_{4}$, and $\mathrm{KOH}$ ) was developed and a dichotomous identification key was used with all types of chemicals in a single test. However, the results showed that the rice samples were classified into 2-4 classes $^{23}$. Consequently, the identification efficacy of these methods was clearly low for hybrid testing ${ }^{6}$. In comparison with the grow-out test, the UTLIEF technique was found to be superior when considering efficacy and total cost. It is well known that in the grow-out test, phenotypical appearance could be affected by environmental factors such as temperature and soil fertility ${ }^{24}$. As mentioned before, the Thai Seed Act has set the maximum allowance of other-variety contamination in certified seed of rice at 20 seeds per 500 g. For KDML105 variety, the weight of 1000 seed is $27.9 \mathrm{~g}^{25}$. Thus the maximum allowable amount for other-variety contamination calculated in this variety is $0.1 \%$. 
When the UTLIEF technique with phosphate buffer was applied to evaluate the possibility of using it to identify for other varieties in rice seed with the method 'testing individual seeds', it was found that 9 seeds of CNT1 could be clearly separated from 91 seeds of KDML105 (Fig. 3). Hence in a variety verification with 100 lanes (or single seed samples) on a plate, a seed lot could be rejected only if the acceptable lowest level of other-variety seed contamination is set at $1 \%$. In other words, this method of individual seed testing could be used to identify the contaminant seed with a $1 \%$ cutoff point; hence it could not be implemented to test for other varieties following the Thai Seed Act unless 10 plates with 1000 lanes were used. However, this would involve an extremely high cost and be laborious.

Testing bulk samples (10 seeds) was introduced to test other-variety contamination at $0.1 \%$. However, it could only differentiate other-variety contamination at proportions of 4:6 seeds (contaminant variety versus main variety, respectively) upwards (Fig. 8 and Fig. 9). Thus contamination must exceed $40 \%$, otherwise this method cannot identify the contaminant seeds of the other variety according to the standards in the seed legislation of Thailand. Although the technique used in the present study was not appropriate to identify contamination with another variety at $0.1 \%$, it might be a possible subject to develop it further to verify other testing pairs or to try other protein extraction buffers. Hence, much remain to be learned about effective buffers to extract the seed storage protein in rice, from both the economic and biological aspects.

\section{CONCLUSIONS}

The UTLIEF is a promising technique for the identification of Thai rice varieties. Phosphate buffer, with a gel $\mathrm{pH} 2-9$, had the highest efficacy when compared to $5 \mathrm{mM} \mathrm{NaCl}$ and deionized water. When applying the UTLIEF technique using phosphate buffer and a gel $\mathrm{pH}$ range $2-9$ to identify othervariety contamination in Thai rice, it was found that this technique combined with the method of testing individual seeds could effectively identify othervariety contamination. However, the ability to reject other-variety contamination in one gel was only at the $1 \%$ cutoff point. The UTLIEF in combination with the method of testing bulk samples (10 seeds) could detect contaminant seeds of another variety where there were at least 4 or more seeds out of 10 seeds. Hence it was unsuccessful for identifying the other-variety contamination at $0.1 \%$ as required under the seed laws of Thailand using one gel.

Acknowledgements: The authors would like to thank Kasetsart University Research and Development Institute for financial support, Norbert Leist and Rainer Knoblauch for invaluable suggestions regarding UTLIEF. The authors also thank the Centre for Agricultural Biotechnology, Kasetsart University, Thailand for providing all the equipment and laboratory space.

\section{REFERENCES}

1. Rice Department (2012) The development of rice production of Thailand to prepare for the international community of ASEAN. In: Papers from Seminars, Workshops and Conferences for Analysis of the Competitiveness of Agricultural Products to Cater for ASEAN, Ministry of Agriculture and Cooperatives, Bangkok, Thailand, [in Thai].

2. Prasertsak A, Palawisut W, Thavong P, Kimise A, Pintaya P, Chattuporn S, Intrman A, Nisaihan P, et al (2011) Seed quality status of rice seed producers, seed sellers and farmers. In: Proceedings of the 2011 Conference on Rice and Cereal Crops of Winter, Bureau of Rice Research and Development, Bangkok, Thailand, pp 42-62, [in Thai].

3. Chanprasert W, Prasertsak A, Romkaew J, Thobunluepop P, Maneenuam T (2014) A survey on rice seed production problem in the Central and Northeast regions. In: Proceedings of the 31st Conference on Rice and Cereal Crops of Winter, Bureau of Rice Research and Development, Bangkok, Thailand, pp 506-25, [in Thai].

4. Coolbear P, Hill MJ (1988) Seed quality control. In: Rice Seed Health, International Rice Germplasm Center, IRRI, Manila, the Philippines, pp 331-42.

5. Arus P (1983) Genetic purity of commercial seed lots. In: Isozymes in Plant Genetics and Breeding (Part A), pp 415-23.

6. Zhao T, Yan M, Lu YP, Yang F, Huang J, Wang XF (2005) Genetic purity testing of two-line hybrid rice seeds by ultrathin-layer isoelectric focusing of proteins. Seed Sci Tech 33, 45-52.

7. van den Berg BM (1990) Inbred testing of tomato (Lycopersicon esculentum L.) F1 varieties by ultrathinlayer isoelectric focusing of seed protein. Electrophoresis 11, 824-9.

8. Onwimol D, Chanpreme S, Tongket T (2010) Seed storage protein extraction and gel $\mathrm{pH}$ gradient for cucumber varietal identification via an ultrathin-layer isoelectric focusing technique. Kasetsart J (Nat Sci) 44, 902-11.

9. Leist N, Knoblauch R (2003) Electrophoretic methods for varietal verification (Part I). In: Proceedings of the 5th ISTA/FAO Workshop on Electrophoretic Methods and PCR-Techniques for Variety Verification 
and GMO Detection, International Seed Testing Association, Augustenberg, Germany, pp 32-9.

10. Wang XF, Knoblauch R, Leist N (2000) Varietal discrimination of tomato (Lycopersicon esculentum L.) by ultrathin-layer isoelectric focusing of seed protein. Seed Sci Tech 28, 521-6.

11. Wang XF, Knoblaunch R, Leist N (2001) Identification of varieties and testing of hybrid purity of rice by ultrathin-layer isoelectric focusing of seed protein. Int Rice Res Newslett 26, 18-9.

12. International Seed Testing Association (2011) International Rules for Seed Testing, ISTA, Bassersdorf, Switzerland.

13. Radola L (1980) Ultrathin-layer isoelectric focusing in 50-100 $\mu \mathrm{m}$ polyacrylamide gels on silanized glass plates or polyester films. Electrophoresis 1, 43-56.

14. Onwimol D (2010) Varietal identification of cucumber using seed protein analysis via ultrathin layer isoelectric focusing technique. MSc thesis, Kasetsart Univ, Khamphangsean, Thailand.

15. David G, Ahuja S (2005) Isoelectric focusing. In: Handbook of Isoelectric Focusing and Proteomics, Elsevier Academic Press, Amsterdam, the Netherlands.

16. Remund KM, Dixon DA, Wright DL, Holden LR (2001) Statistical considerations in seed purity testing for transgenic traits. Seed Sci Res 11, 101-19.

17. van den Berg BM (1991) A rapid and economical method for hybrid purity testing of tomato (Lycopersicon esculentum L.) F1 hybrid using ultrathin-layer isoelectric focusing of alcohol dehydrogenase variants from seeds. Electrophoresis 12, 64-9.

18. Tiwari JK, Rastogi NK, Chandrakar PK, Xalxo MS, Saxena RR, Verulkar SB (2014) Assessment of genetic purity of four rice cultivars using microsatellite and ISSR markers. Seed Sci Tech 42, 227-36.

19. Bradford MM (1976) A rapid and sensitive method for the quantitation of microgram quantities of protein utilizing the principle of protein-dye binding. Anal Biochem 72, 248-54.

20. Manum P (2008) Varietal identification of sweet corn using seed protein analysis via ultrathin layer isoelectric focusing. MSc thesis, Kasetsart Univ, Khamphangsean, Thailand.

21. Beever L (1976) Nitrogen Metabolism in Plants, Arnold, London.

22. Garcia MC, Figueroa JM, Gomez RL, Townsend R, Schoper J (1998) Pollen control during transgenic hybrid maize development in Mexico. Crop Sci 38, 1597-602.

23. Vijayalakshmi B, Vijay D (2009) Development of seed keys for varietal identification in rice (Oryza sativa) using chemical tests. Seed Res 37, 56-61.

24. Pabendon MB, Mejaya MJ, Koswara J, Aswidinnoor $\mathrm{H}$ (2010) Correlation between genetic distances based on microsatellite marker in maize inbred with seed weight of F1. J Penelit Pertan Tanam Pangan 29, 11-7, [in Indonesian]
25. Rice Department (2010) Botanical Characteristics of KDML 105, Ministry of Agriculture and Cooperatives, Bangkok, Thailand. 